\title{
Dielectric Loading on Multi-Band Behaviors of Pentagonal Fractal Patch Antennas
}

\author{
Ravindra Kumar Yadav ${ }^{1}$, Jugul Kishor ${ }^{2}$, R. L. Yadava ${ }^{3}$ \\ ${ }^{1}$ Department of Electronics and Communication Engineering, JRE School of Engineering, Greater Noida, India; ${ }^{2}$ Department of \\ Electronics and Communication Engineering, ITS Engineering College, Greater Noida, India; ${ }^{3}$ Department of Electronics and Com- \\ munication Engineering, Galgotia's College of Engineering and Technology, Greater Noida, India. \\ Email:ravipusad@gmail.com,jugulkishor@gmail.com,rly1972@gmail.com
}

Received October $20^{\text {th }}, 2013$; revised November $18^{\text {th }}, 2013$; accepted December $13^{\text {th }}, 2013$

Copyright (C) 2013 Ravindra Kumar Yadav et al. This is an open access article distributed under the Creative Commons Attribution License, which permits unrestricted use, distribution, and reproduction in any medium, provided the original work is properly cited.

\begin{abstract}
This paper describes the multiband behaviour as well as the response for dielectric loading of a pentagonal fractal patch antenna designed at frequency $f=2.45 \mathrm{GHz}$. The proposed antenna shape has been obtained by introducing slots in a pentagonal patch antenna up to second iteration. Detailed design steps and results of the designs are studied and investigated in this paper. Simulated and measured results reveal that the antenna will be operated at three different frequency bands $-2.17 \mathrm{GHz}, 3.56 \mathrm{GHz}$, and $7.93 \mathrm{GHz}$ with acceptable performances (i.e. VSWR $<2$ ). The measured results for the antennas are in good agreement with simulated results. The proposed antenna maintains good radiation pattern with gain. However dielectric loading increases its radiation efficiency at the cost of significant decrease in gain and directivity.
\end{abstract}

Keywords: Fractal Patch Antenna; Multiband; Pentagonal Patch and Dielectric Loading

\section{Introduction}

The modern telecommunication system requires antennas that have multiband and wider bandwidth characteristics as well as smaller dimensions than conventionally possible ones. In the recent years, the self-similar and space filling nature of fractal geometry has motivated antenna designers to adopt this geometry as a viable alternative to meet the target of multiband operation. The self-similar and scaling properties of fractal geometries characterize these structures [1]. In 1998, Z. Baharav presented his work on fractal arrays based on iterated function systems. Self-similar feature in the radiation patterns allows a multi-band frequency usage of the fractal array [2]. In 1999, M. Navarro et al. worked on the topic "Self-similar surface current distribution on the fractal Sierpinski antenna verified with Infra-red Thermograms" [1]. In this research, he presented the experimental verification of the fractal Sierpinski Antenna surface's current distribution. In 2001, P. Felber reported that due to the space filling properties of fractals, antennas designed from certain fractal shapes can have far better electrical to physical size ratios than conventional antennas [3]. In 2004, K. Sathya performed research on size reduction of low fre- quency microstrip patch antenna with Koch shaped fractal slot and a size reduction about 84\% [4]. In 2005, P. Hazadra and M. Mazánek performed the research on model analysis of fractal microstrip patch antennas and the obtained results found in good agreement with the simulated one [5]. Later in 2006, V. Gupta and N. Gupta conducted research on "Two compact microstrip patch antenna for $2.4 \mathrm{GHz}$ band", in which two low profile patch antennas for wireless LAN 802.11b communication standard were designed and investigated, however, performed analysis of a fractal microstrip patch antenna was done in 2007 [6,7]. In 2008, F. H. Kashani et al. studied a novel broadband fractal Sierpinski shaped, microstrip antenna, and found that this antenna with a multilayer structure behaves in $7-10.6 \mathrm{GHz}$ portion which overlaps the UWB range [8].

However in 2009, A. Azari designed an ultra wide band hexagonal fractal microstrip antenna and found that the antenna has multiband behavior, and significant gain improvement was also achieved [9]. In 2010, F. J. Jibrael et al. presented a research paper entitled " $A$ new multiband patch microstrip plusses fractal antenna", and proposed that the antenna has an excellent size reduction 
possibility with good radiation performance for wireless applications [10]. However, L. Economou et al. [11] analyzed circular patches printed on RT Duroid, with glass laminated superstrates and found that the glass improved the bandwidth of the antenna. Latter, D. D. Krishna et al. [12] proposed a dielectric loaded slotted circular dual frequency microstrip antenna and observed that the superstrate, not only acts as a random, but also improves the operating bandwidth of the antenna. Several research works have been reported on fractal patch antennas and the microstrip patch antenna, but not much attention has been paid on dielectric loaded fractal patch antennas, though such loading severely affects the performance characteristics of the patch antennas.

Therefore, in this paper authors have designed the pentagonal fractal patch antennas and made an attempt to investigate the effects of dielectric loading on the behavior of the antenna. The novelty of this work presented here is that the environmental effect on fractal patch antenna has been analyzed. We considered here rain attenuation as an environmental parameter and analysed performance degradation of fractal patch antenna. Figure 1 shows the geometrical configuration of proposed pentagonal fractal patch antenna up to second iterations.

\section{Design of Antenna Geometry}

A pentagonal microstrip patch antenna gives better performance than the rectangular patch antenna; in particular, it supports both linear and circular polarizations [13] (Figure 2). The pentagonal patch antenna provides circular polarization with only one feed where as rectangular patch antenna requires multiple feeds to get circular polarizations. Hence the proposed antenna geometry is chosen to be a pentagonal patch antenna and fed with a $50 \Omega$ coaxial cable for better impedance matching. This has later been converted into fractal patch antenna accompanying pentagonal slots using a finite number of iterations. The pentagonal antenna size calculations were made considering the invariance of the electrostatic energy below the pentagonal and circular patches, keeping their areas remain constant [14]. The relationship between the circles $\left(r_{1}\right)$ to the side arm of the regular pentagon $\left(r_{2}\right)$ is given in Equation (1).

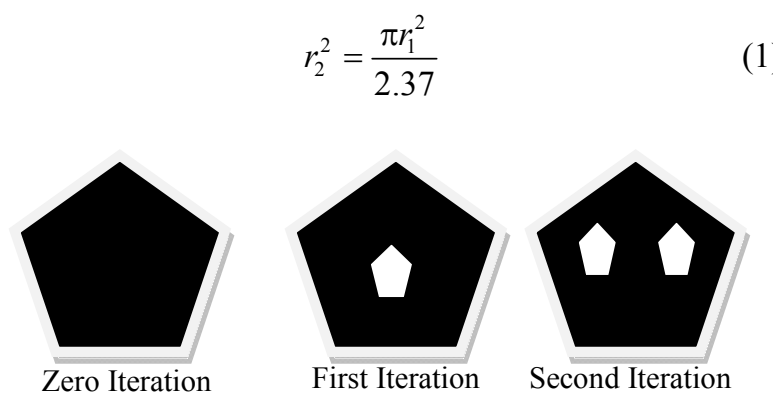

Figure 1. Geometry of proposed fractal antennas.
Side arm of the pentagon $\left(r_{2}\right)=1.175 r_{1}$.

In the derivation of the expression (1), the pentagonal patch is assumed to be a resonant cavity with perfectly conducting side walls.

Because a circular disc is the limiting case of the polygon with large number of sides, in this case number of sides are 5. The resonant frequency of the dominant as well as for the higher order modes can be calculated from the formula given below:

$$
f_{n p}=\frac{X_{n p}^{\prime} c}{2 \pi r_{1} \sqrt{\varepsilon_{r}}}
$$

where $X_{n p}^{\prime}$ are the zeros of the derivative of the Bessel function $J_{n}(x)$ of the order $n$, as is true for TE mode circular waveguides, however for the lowest order modes;

$$
X_{n p}^{\prime}=1.84118
$$

The lengths of each side of the pentagonal antenna are calculated by using Equations (1) \& (2). For coaxial feeds, the location of the feed point is usually selected to provide a good impedance match.

\section{Fractal Antenna Generation and Antenna Geometry}

In this we illustrate the design procedure of the fractal patch antenna for multiband application. In this design procedure a pentagonal antenna is converted into the fractal patch antenna by the introduction of the pentagonal sot. In $1^{\text {st }}$ iteration a pentagonal slot is introduced in the centre of the patch. For the modification of the basic geometry, the size of the slot is $1 / 5$ to the size of the basic geometry. Similarly, in the second stage, a set of two pentagon slots is inserted; the size of the each slot is $1 / 6$ to the size of the basic geometry. Due to these slots, the antenna posses the characteristics of multi-band frequency operation.

Using design parameters (Table 1) a pentagonal antenna is designed and simulated using HFSS, which has been taken as 0th iteration or the base geometry of pro-

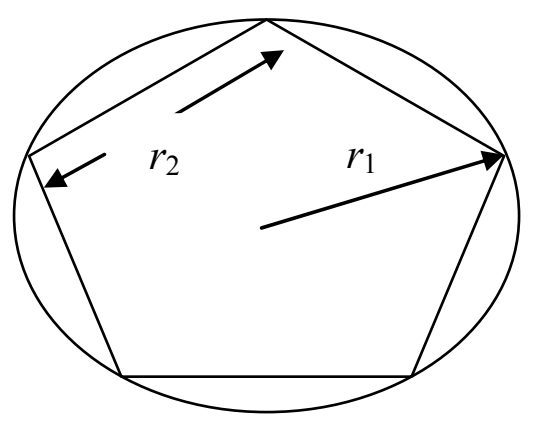

Figure 2. Geometry of a regular pentagonal shape. 
Table 1. Design specifications for proposed antennas.

\begin{tabular}{cc}
\hline Geometry & Pentagonal \\
\hline Side arm length & $22.58 \mathrm{~mm}$ \\
Substrate (FR-4) & $\varepsilon_{r}=4.4, h=0.8 \mathrm{~mm}$, \\
$\tan \delta=0.002$ \\
Centre frequency & $2.45 \mathrm{GHz}$ \\
Feed location (from center) & $8.21 \mathrm{~mm}$ \\
Coaxial cable dimension & Inner radius: $0.5 \mathrm{~mm}$ \\
& Outer radius: $0.9 \mathrm{~mm}$ \\
Dielectric cover (distilled water) & $\varepsilon_{r}=81, h=0.1 \mathrm{~mm}$ to $0.3 \mathrm{~mm}$ \\
\hline
\end{tabular}

posed fractal patch antenna as shown in the Figure 3. Each side of the patch is of $22.58 \mathrm{~mm}$, and the antenna has been designed on a FR-4 substrate with relative permittivity $\left(\varepsilon_{r}\right) 4.4$, loss tangent 0.002 and substrate thickness of $0.8 \mathrm{~mm}$ using the Equations (1) \& (2).

To obtain dual band behavior the $1^{\text {st }}$ iteration of this fractal patch has been obtained by etching a pentagonal slot having side arm $4.7 \mathrm{~mm}$ without changing the original structure of the patch as shown in the Figure 4.

However for multiband behavior $2^{\text {nd }}$ iteration of the fractal patch has been obtained by etching two pentagonal slot having side arm $3.4 \mathrm{~mm}$ without changing the original structure of the patch as shown in the Figure 5.

\section{Results and Discussions}

\subsection{Pentagonal Fractal Patch Antennas}

The geometry shown in Figures 3-5 is simulated using the HFSS software and the return loss characteristics obtained has been shown in the Figure 6. From which return loss of $-18.37 \mathrm{~dB}$ at a resonant frequency of 2.44 $\mathrm{GHz}$ has been obtained for $0^{\text {th }}$ iteration. From the return loss characteristics one may find the presence of dual bands having return loss of $-10.88 \mathrm{~dB}$ at $2.30 \mathrm{GHz}$, $-18.10 \mathrm{~dB}$ at $3.88 \mathrm{GHz}$ for $1^{\text {st }}$ iteration. However for the $2^{\text {nd }}$ iterated simulation results we find the antenna is resonating at three different resonant frequencies. We may view the return loss of $-16.69 \mathrm{~dB}$ at $2.17 \mathrm{GHz},-16.17$ $\mathrm{dB}$ at $3.56 \mathrm{GHz},-19.64 \mathrm{~dB}$ at $7.9315 \mathrm{GHz}$, which satisfy the requirement of multi-banding behavior of antenna.

Figure 7 illustrates comparison of measured and simulated results, which are in good agreement and verify the multi band behavior of the $2^{\text {nd }}$ iterated fractal patch antenna with return loss of $-18.2 \mathrm{~dB}$ at $2.17 \mathrm{GHz},-24.81$ $\mathrm{dB}$ at $3.61 \mathrm{GHz}$ and $-19.64 \mathrm{~dB}$ at $7.93 \mathrm{GHz}$. Simulated and measured return loss are also tabulated in Tables 2 and 3 respectively.

Figure 8 shows the simulated input impedance of the fractal patch antenna for $0^{\text {th }}, 1^{\text {st }}$ and $2^{\text {nd }}$ iteration. Simulated results of the input impedances are also tabulated in

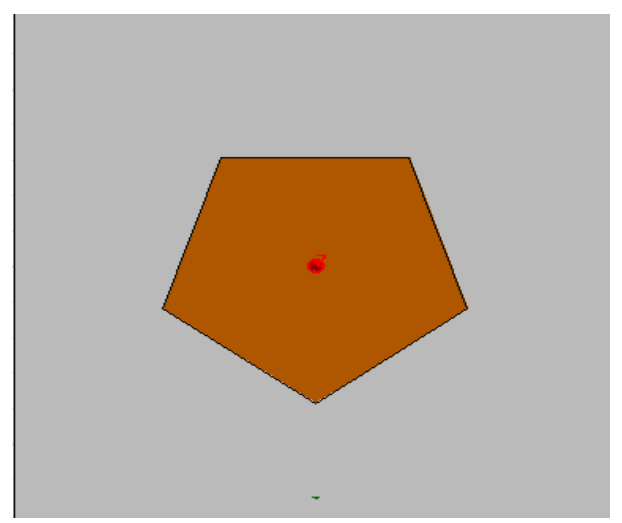

Figure 3. Geometry of $0^{\text {th }}$ iteration pentagonal patch antenna.

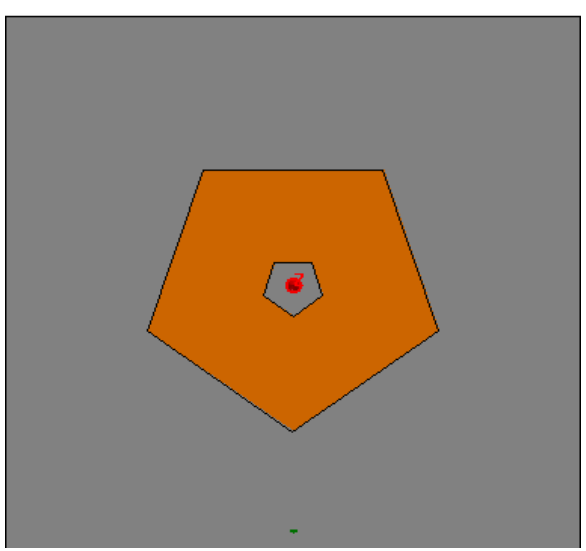

Figure 4. Geometry of $1^{\text {st }}$ iteration pentagonal patch antenna.

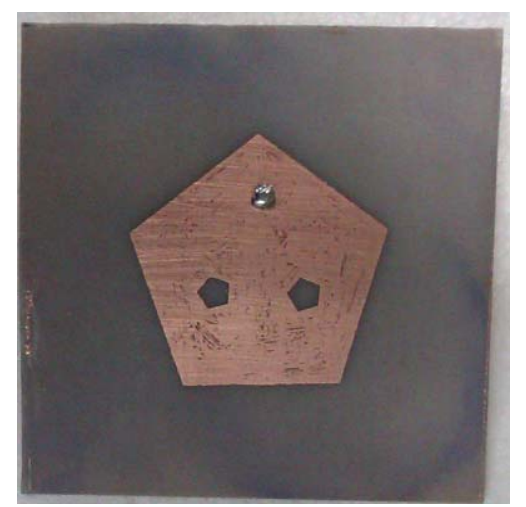

Figure 5. Geometry of $2^{\text {nd }}$ iteration pentagonal patch antenna.

\section{Table 2 .}

Figure 9 shows the simulated VSWR of the fractal patch antenna for $0^{\text {th }}, 1^{\text {st }}$ and $2^{\text {nd }}$ iteration and observed that VSWR is less than 2 at the resonant frequencies. Simulated VSWR results are also tabulated in the Table 2.

The radiation pattern of the $0^{\text {th }}$ iteration of fractal patch antenna has been shown in the Figure 10. From this rad- 


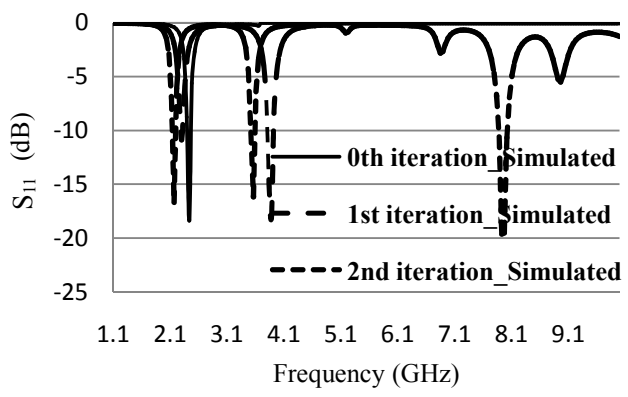

Figure 6. Comparisons of simulated return loss characteristics of the fractal patch antennas.

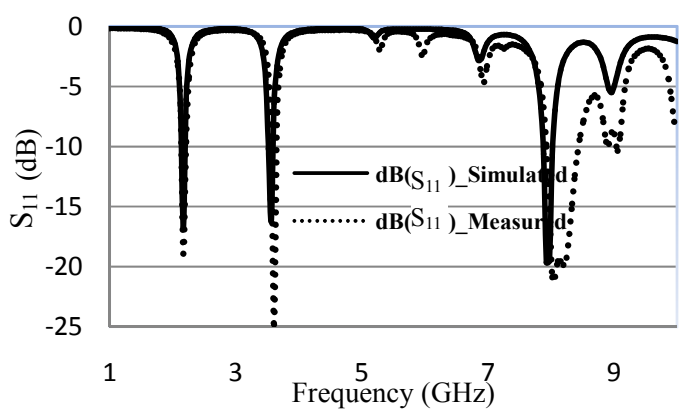

Figure 7. Comparisons of measured and simulated return loss characteristics of the $2^{\text {nd }}$ iterated fractal patch antenna.

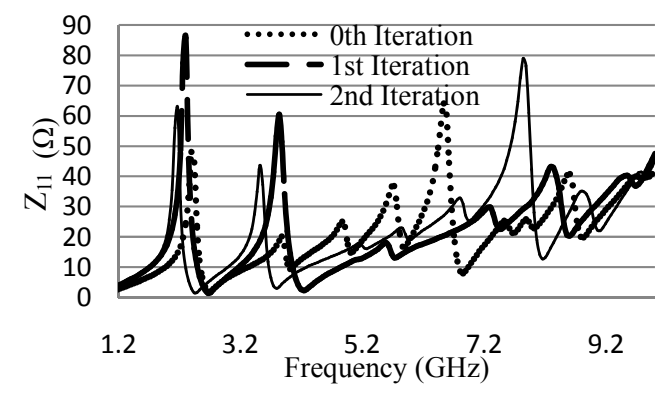

Figure 8. Comparisons of Input Impedance of the fractal patch antenna.

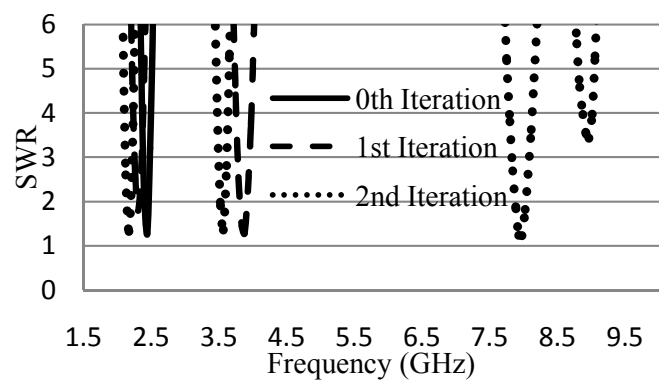

Figure 9. Comparison of VSWR of the fractal patch antenna.

iation pattern we can find that the maximum achieved gain is $1.3 \mathrm{dBi}$. The radiation pattern of $1^{\text {st }}$ iteration of fractal patch antenna at both resonant frequencies has been shown in the Figure 11, which gives the maximum gain of $2.15 \mathrm{dBi}$ at $2.3 \mathrm{GHz}$ and $4.0 \mathrm{dBi}$ at $3.88 \mathrm{GHz}$.

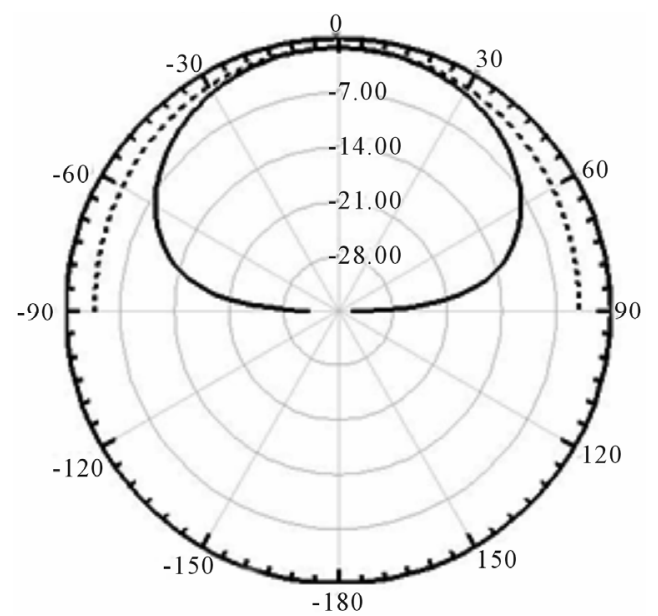

Figure 10. Radiation pattern at E-plane and $\mathrm{H}$-plane for $0^{\text {th }}$ iteration at $2.44 \mathrm{GHz}$.

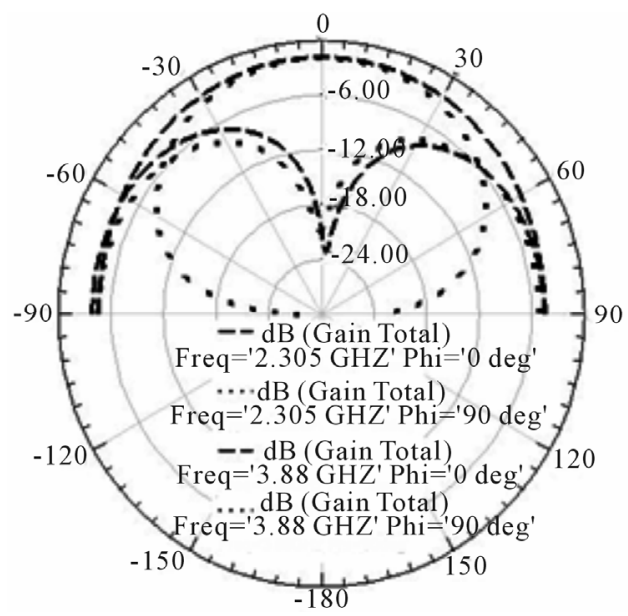

Figure 11. Radiation pattern at E-plane and H-plane for $1^{\text {st }}$ iteration at $2.30 \mathrm{GHz}$ and $3.88 \mathrm{GHz}$.

Table 2. Simulated return loss, impedance and VSWR of the proposed fractal patch antenna.

\begin{tabular}{ccccc}
\hline Types & $\begin{array}{c}\text { Frequency } \\
(\mathrm{GHz})\end{array}$ & $S_{11}(\mathrm{~dB})$ & $\begin{array}{c}\text { Impedance } \\
(\Omega)\end{array}$ & VSWR \\
\hline $0^{\text {th }}$ Iteration & 2.44 & -18.37 & 44.61 & 1.27 \\
& 2.30 & -10.88 & 85.73 & 1.79 \\
$1^{\text {st }}$ Iteration & 3.88 & -18.10 & 51.52 & 1.28 \\
& 2.17 & -16.69 & 62.46 & 1.33 \\
$2^{\text {nd }}$ Iteration & 3.56 & -16.17 & 37.20 & 1.36 \\
& 7.93 & -19.64 & 42.00 & 1.23 \\
\hline
\end{tabular}

The radiation pattern and gain of the $2^{\text {nd }}$ iteration, at all three resonant frequencies have been illustrated in the Figures 12 and 13. One may be able to observe that maximum achieved gain at $2.17 \mathrm{GHz}$ is $2 \mathrm{dBi}$, at 3.56 $\mathrm{GHz}$ is $5.00 \mathrm{dBi}$, and at $7.93 \mathrm{GHz}$ is $1.0 \mathrm{dBi}$. Table 4 
Table 3. Measured return loss for $2^{\text {nd }}$ iteration fractal antenna.

\begin{tabular}{ccc}
\hline Type & Simulated Frequency $(\mathrm{GHz})$ & $S_{11}(\mathrm{~dB})$ \\
\hline \multirow{3}{*}{$2^{\text {nd }}$ Iteration } & 2.17 & -18.92 \\
& 3.61 & -24.81 \\
& 7.93 & -19.64 \\
\hline
\end{tabular}

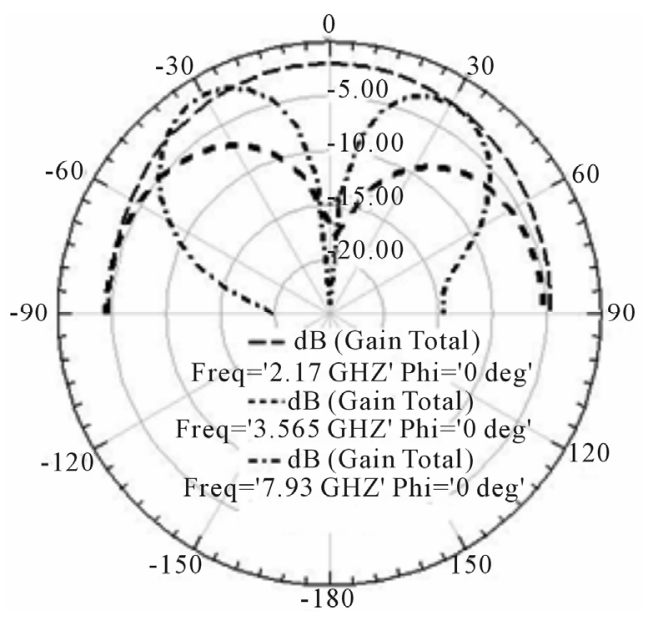

Figure 12. Radiation pattern at E-plane for $2^{\text {nd }}$ iteration at 2.17 GHz, 3.56 GHz and $7.93 \mathrm{GHz}$.

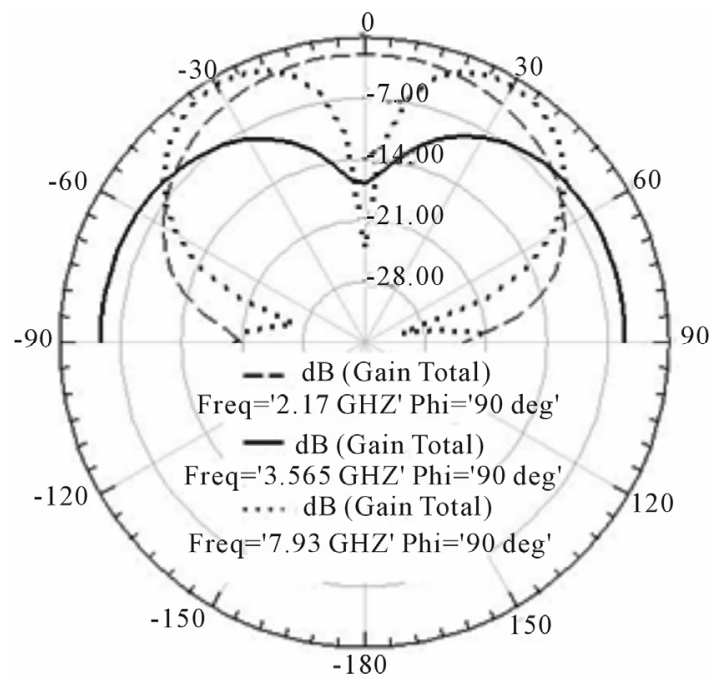

Figure 13. Radiation pattern at $\mathrm{H}$-plane for $2^{\text {nd }}$ iteration at 2.17 GHz, 3.56 GHz and $7.93 \mathrm{GHz}$.

presents various parameters like directivity, gain and radiated power at all resonant frequencies. While experimental set up used for measurement and obtained results are shown in Figures 14 and 15 respectively.

\subsection{Pentagonal Fractal Patch Antennas with Dielectric Loading}

The dielectric loading changes the resonance frequency,
Table 4. Simulated directivity, gain, radiated power and radiation efficiency of the fractal patch antenna.

\begin{tabular}{ccccc}
\hline Types & $\begin{array}{c}\text { Frequency } \\
(\mathrm{GHz})\end{array}$ & Directivity & $\begin{array}{c}\text { Gain } \\
(\mathrm{dBi})\end{array}$ & $\begin{array}{c}\text { Radiated } \\
\text { power }(\mathrm{mW})\end{array}$ \\
\hline $\begin{array}{c}0^{\text {th }} \\
\text { Iteration }\end{array}$ & 2.44 & 0.81 & 1.3 & 10.00 \\
$\begin{array}{c}1^{\text {st }} \\
\text { Iteration }\end{array}$ & 2.30 & 0.75 & 2.15 & 5.00 \\
$2^{\text {nd }}$ & 3.88 & 0.49 & 4.00 & 7.8 \\
Iteration $^{2.17}$ & 3.56 & 0.74 & 2.00 & 6.9 \\
\hline
\end{tabular}

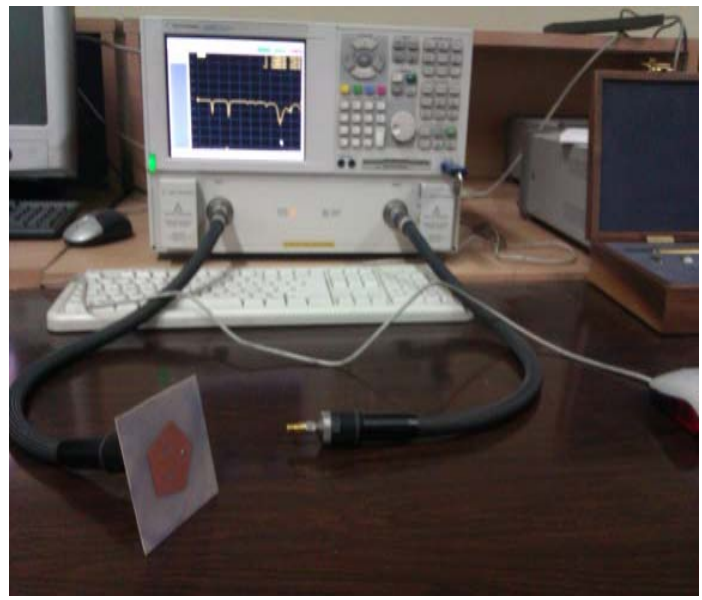

Figure 14. Antenna measurement setup.

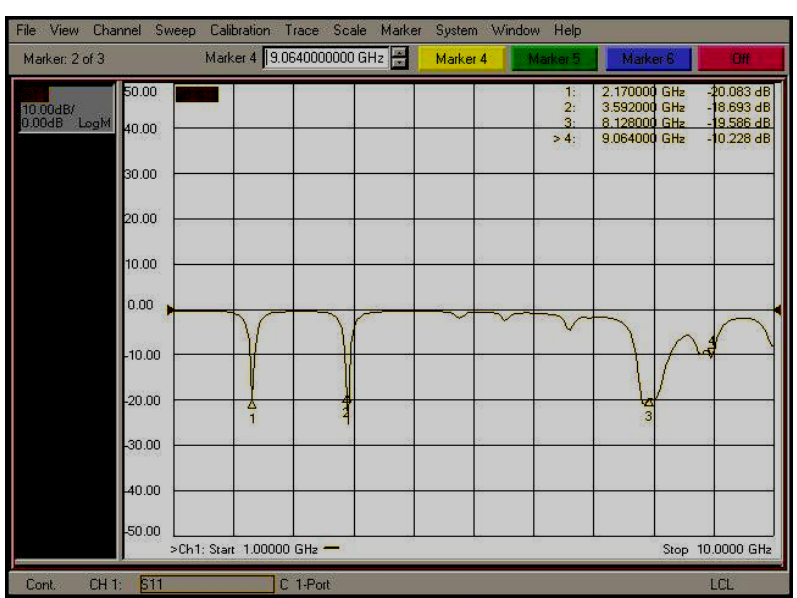

Figure 15. Measured results of the $2^{\text {nd }}$ iterated fractal patch antenna.

gain, radiation efficiency and bandwidth of the conventional patch antennas, and amount of effects vary with thickness of dielectric, types of dielectrics, impedance matching and polarization. The study shows that resonant frequency decreases with increasing the thickness of dielectric. The maximum value of the radiation efficiency 
is obtained in the case of an antenna with different substrate and dielectric materials than that of an antenna with substrate and dielectric of same dielectric. As reported in reference [15], due to dielectric loading, capacitance of the antenna system increases, which decreases the overall performances of the antenna such as resonant frequency, impedance bandwidth and radiating efficiency.

Hence, in order to observe the effects of dielectric loadings on the antenna characteristics, the proposed antenna has been analyzed and tested using water as a dielectric cover. The obtained characteristics are shown in Figures 16-19; and the simulated and measured results are also tabulated in Tables 5 and $\mathbf{6}$ respectively. Measured results for the fractal patch antennas without and with a dielectric cover of thickness $0.3 \mathrm{~mm}$ are shown in Figures 17 and 20. Measured results shows shift in resonance frequency, which are due to non uniform distribution of water layer on the patch antenna surface and inability to measure exact water level thickness on the patch surface.

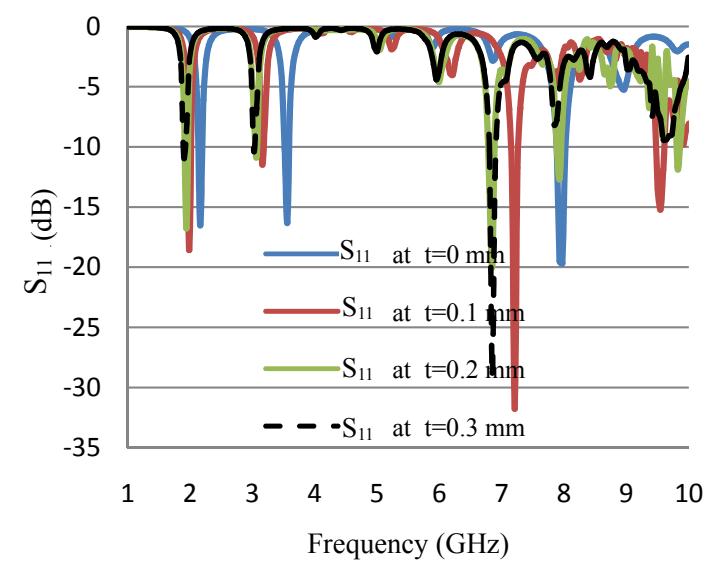

Figure 16. Comparisons of simulated return loss characteristics of the fractal patch antenna with dielectric cover.

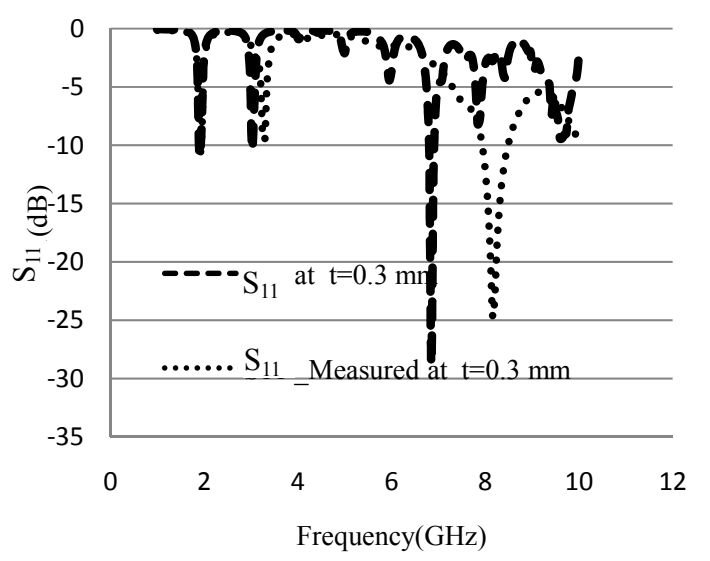

Figure 17. Comparisons of measured and simulated return loss characteristics of the $2^{\text {nd }}$ iterated fractal patch antenna for dielectric cover of $0.3 \mathrm{~mm}$.

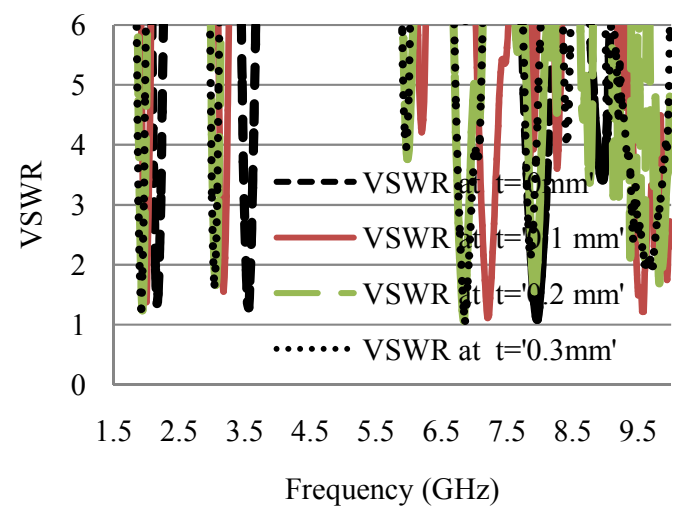

Figure 18. Frequency response of VSWR with dielectric cover.

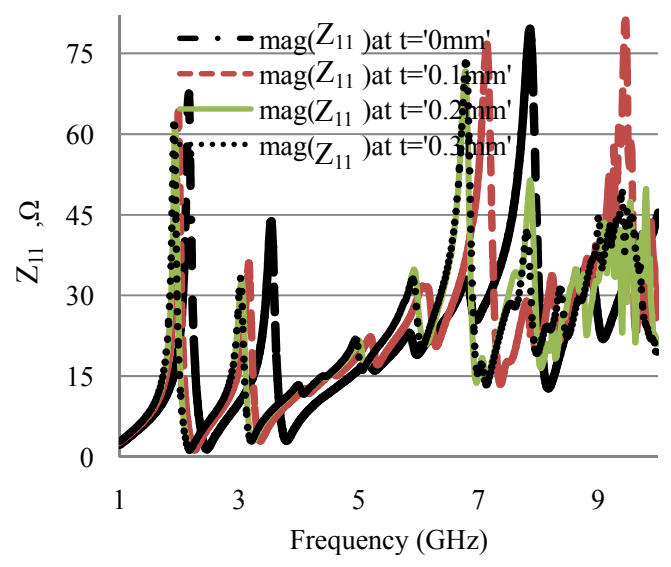

Figure 19. Input impedance with dielectric covers.

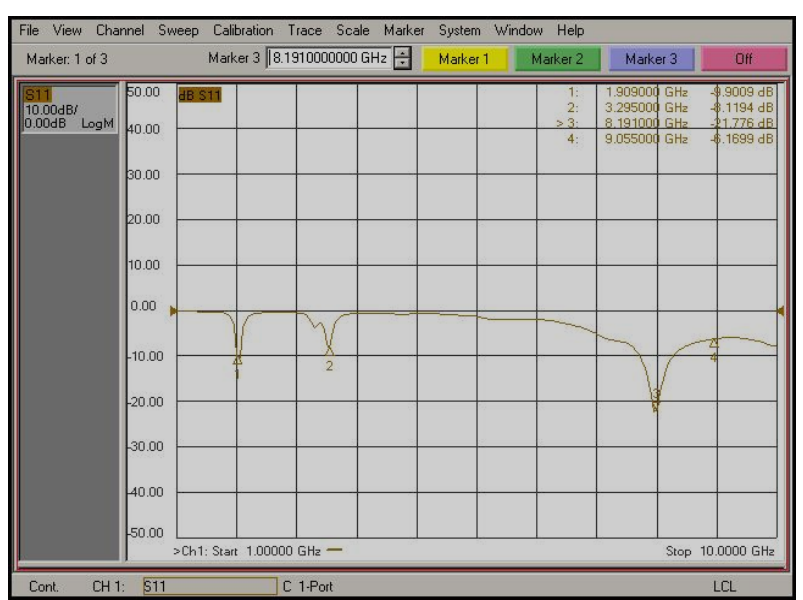

Figure 20. Measured results of the fractal patch antennas with dielectric cover of $0.3 \mathrm{~mm}$.

\section{Conclusion}

In this work, we analyse the effect of water accumulation on the surface of the fractal patch antenna. Accumulation of rain water on the top of the antenna surface for highly resonant (high Q-value) microstrip antennas makes them prone to frequency shift as well as impedance mismatch. 
Table 5. Simulated return loss, impedance and VSWR of the proposed fractal patch antenna for second iteration with a dielectric cover of thickness $0.1 \mathrm{~mm}$ to $0.3 \mathrm{~mm}$.

\begin{tabular}{|c|c|c|c|c|}
\hline $\begin{array}{c}\text { Cover } \\
\text { thickness } \\
\text { (water) }\end{array}$ & $\begin{array}{c}\text { Simulated } \\
\text { frequency } \\
(\mathrm{GHz})\end{array}$ & $S_{11}(\mathrm{~dB})$ & $\begin{array}{c}\text { Impedance } \\
(\Omega)\end{array}$ & $S W R$ \\
\hline \multirow{3}{*}{0} & 2.17 & -16.69 & 62.46 & 1.33 \\
\hline & 3.56 & -16.17 & 37.20 & 1.36 \\
\hline & 7.93 & -19.64 & 60.0 & 1.23 \\
\hline \multirow{3}{*}{0.1} & 2.0 & -16.00 & 55.71 & 1.37 \\
\hline & 3.18 & -13.27 & 32.27 & 1.55 \\
\hline & 7.2 & -25.47 & 55.57 & 1.11 \\
\hline \multirow{3}{*}{0.2} & 1.94 & -19.59 & 58.93 & 1.23 \\
\hline & 3.06 & -12.10 & 30.67 & 1.66 \\
\hline & 6.84 & -29.85 & 47.08 & 1.06 \\
\hline \multirow{3}{*}{0.3} & 1.92 & -18.83 & 61.53 & 1.25 \\
\hline & 3.04 & -12.05 & 30.73 & 1.66 \\
\hline & 6.86 & -31.40 & 47.86 & 1.05 \\
\hline
\end{tabular}

Table 6. Measured return loss for $2^{\text {nd }}$ Iteration dielectric cover of thickness $0.3 \mathrm{~mm}$.

\begin{tabular}{ccc}
\hline Type & Measured Frequency $(\mathrm{GHz})$ & $S_{11}(\mathrm{~dB})$ \\
\hline \multirow{3}{*}{0.3 mm gap } & 1.9 & -10.88 \\
& 3.29 & -9.50 \\
& 8.15 & -24.70 \\
\hline
\end{tabular}

A prototype of the proposed antenna was fabricated and measured for experimental verification. Based on the measurement results, substantial improvements in the design of fractal antenna are taken care while analysing. The pentagonal fractal antenna designed at frequency $f=$ $2.45 \mathrm{GHz}$, can be used at three different frequency bands (multiband) $-2.17 \mathrm{GHz}, 3.56 \mathrm{GHz}$, and $7.93 \mathrm{GHz}$ with acceptable performances (i.e. VSWR $<2$ and $S_{11}<-10$ $\mathrm{dB})$, particularly in wireless communications. Result of dielectric loaded antenna reveals that the dielectric loading changes the parameters - resonant frequency, return loss, impedance, VSWR etc. of the antenna. Dielectric loading increases its radiation efficiency at the cost of significant decrease in gain and directivity. It has also been observed that as the dielectric thickness increases, the resonant frequency shifts towards lower side and hence deteriorates the multi-band characteristics of the pentagonal fractal antennas. The measured results for the antennas are in good agreement with simulated results especially for $2^{\text {nd }}$ iterated patch antenna with dielectric cover (water) having thickness $0.3 \mathrm{~mm}$.

\section{Acknowledgements}

The authors express their appreciation to Dr. B. K. Kanaujia, Professor, Department of Electronics and Communication, Ambedkar Institute of Technology, New Delhi for allows us to use HFSS simulation software and experimentations.

\section{REFERENCES}

[1] M. Navarro, J. M. Gonzalez, C. Puente, J. Romeu and A. Aguasca, "Self-Similar Surface Current Distribution on Fractal Sierpinski Antenna Verified with Infra-Red Thermograms," Electronics Letters, Vol. 35, No. 17, 1999, pp. 1393-1394. http://dx.doi.org/10.1049/el:19990943

[2] Z. Baharav, "Fractal Arrays Based on Iterated Functions System (IFS)," Antennas and Propagation Society International Symposium, Vol. 4, 1999, pp. 2686-2689.

[3] P. Felber, "Fractal Antennas - A Literature Study," A Project Report for ECE 576 Illinois Institute of Technology, 2001.

[4] K. Sathya, "Size Reduction of Low Frequency Microstrip Patch Antennas with Koch Fractal Slots," M. Tech Thesis, Indian Institute of Science, Bangalore.

[5] P. Hazdra and M. Mazánek, "The Miniature Inverted Koch Square Microstrip Patch Antenna," Proceedings of ISAP 2005, Seoul, 2005, pp.121-124.

[6] V. R. Gupta and N. Gupta, "Two Compact Microstrip Patch Antennas for $2.4 \mathrm{GHz}$ Band-A Comparison," Microwave Review, 2006, pp. 29-31.

http://www.mtt-serbia.org.rs/microwave_review/pdf/Vol1 2No2-05-VGupta.pdf

[7] V. R. Gupta and N. Gupta, "Analysis of a Fractal Microstrip Patch Antenna," International Journal of Microwave and Optical Technology, Vol. 2, No. 2, 2007, pp. 124129.

[8] F. H. Kashani, et al., "A Novel Broadband Fractal Sierpinski Shaped, Microstrip Antenna," Progress in Electromagnetics Research, Vol. 4, 2008, pp. 179-190.

[9] A. Azari, "Ultra Wideband Fractal Microstrip Antenna Design," Progress Electromagnetics Research, Vol. 2, 2008, pp. 7-12. http://dx.doi.org/10.2528/PIERC08031005

[10] J. F. Jibrael and M. H. Hammed, "A New Multiband Patch Microstrip Plusses Fractal Antenna for Wireless Applications," ARPN Journal of Engineering and Applied Sciences, Vol. 5, No. 8, 2010, pp. 17-21.

[11] L. Economou, et al., "Circular Microstrip Patches Antennas on Glass for Vehicle Applications," IEE Proceedings of Microwave Antennas Propagation, Vol. 145, No. 5, 1998, pp. 416-420. http://dx.doi.org/10.1049/ip-map:19982250

[12] D. D. Krishna, et al., "Compact Dual Band Slot-Loaded Circular Microstrip Antenna with a Superstrate," Progress in Electromagnetic Research, Vol. 83, 2008, pp. 245 255. http://dx.doi.org/10.2528/PIER08052201

[13] M. Tecpoyotl-Torres, et al., "Pentagonal Microstrip An- 
tenna Equivalent to a Circular Microstrip Antenna for GPS Operation Frequency," Programación Matemática y Software, Vol. 1, No. 2, 2009, pp. 200-208.

[14] G. Kumar and K. P. Ray, "Broadband Microstrip Antennas," Artech House Publishers, London, 2003.
[15] I. Bahl, P. Bhartia and S. Stuchly, "Design of Microstrip Antennas Covered with a Dielectric Layer," IEEE Transactions on Antennas and Propagation, Vol. 30, No. 2, 1982, pp. 314-318.

http://dx.doi.org/10.1109/TAP.1982.1142766 